This item was submitted to Loughborough's Research Repository by the author.

Items in Figshare are protected by copyright, with all rights reserved, unless otherwise indicated.

\title{
Implicit core self-evaluations and work outcomes: Validating an indirect measure
}

PLEASE CITE THE PUBLISHED VERSION

https://doi.org/10.1111/joop.12244

\section{PUBLISHER}

CThe British Psychological Society. Published by John Wiley \& Sons Ltd.

\section{VERSION}

AM (Accepted Manuscript)

\section{PUBLISHER STATEMENT}

This is the peer reviewed version of the following article: DIETL, E. and MEURS, J.A., 2018. Implicit core selfevaluations and work outcomes: Validating an indirect measure. Journal of Occupational and Organizational Psychology, 92 (1), pp.169-190, which has been published in final form at https://doi.org/10.1111/joop.12244. This article may be used for non-commercial purposes in accordance with Wiley Terms and Conditions for Use of Self-Archived Versions

\section{LICENCE}

CC BY-NC-ND 4.0

\section{REPOSITORY RECORD}

Dietl, Erik, and James A. Meurs. 2019. "Implicit Core Self-evaluations and Work Outcomes: Validating an Indirect Measure”. figshare. https://hdl.handle.net/2134/35701. 
Implicit Core Self-Evaluations and Work Outcomes: Validating an Indirect Measure

\author{
Erik Dietl \\ Loughborough University, \\ Loughborough, United Kingdom \\ James A. Meurs \\ Kennesaw State University, \\ Kennesaw, USA \\ Manuscript accepted for publication in \\ Journal of Occupational and Organizational Psychology - October 2018
}

The manuscript may not exactly replicate the final version published in the journal. It is not the copy of record. The final article will be available, upon publication, via its DOI.

\title{
Acknowledgements
}

We would like to express our gratitude to Konrad Senf for proofreading a previous draft of this paper. We also thank Madlen Chabo, Denis Czogala, Simon Feldmann, Mark Hensel, Lisa Ingildeeva, Tina Müller, Mike Morlock, Jan Peichl, Fabian Schmid, Alexander Volk, and Daria Vozian for their help in collecting data. Correspondence concerning this article should be directed to: Erik Dietl, School of Business and Economics, Loughborough University, Loughborough, Leicestershire, LE11 3TU, United Kingdom, E-mail: e.diet1@,lboro.ac.uk 


\begin{abstract}
Core self-evaluations (CSE) represents the fundamental appraisals individuals make about their self-worth and capabilities. Although scholars characterize CSE as evaluations that are both conscious and subconscious, the implicit aspect of CSE has not yet been examined. Drawing on models of dual information processing, we develop and validate an indirect measure (Implicit Association Test) assessing implicit CSE. Therefore, we investigate how explicit, implicit, and acquaintance-rated CSE relate to task performance, organizational citizenship behaviours (OCB), and income. We argue that implicit CSE incrementally predicts these three outcomes beyond explicit and acquaintance-rated CSE. We found that implicit CSE incrementally predicted OCB and income above and beyond explicit CSE. Our effects for implicit CSE held even when controlling for acquaintance ratings of CSE. Also, acquaintance ratings revealed some incremental validity for predicting income and OCB beyond explicit CSE. We discuss implications for CSE measurement and research, and the practical implications of our findings.

Practitioner points:
\end{abstract}

- In evaluative situations, such as personnel selection, self-reported core selfevaluations (CSE) are susceptible to impression management and social desirability.

- We developed an indirect measure (i.e., an Implicit Association Test) to assess implicit CSE and demonstrated its incremental validity for predicting job performance and income beyond self-reported and other-rated CSE.

- Organizations and practitioners should measure self-rated, implicit, and other-rated CSE to predict job performance and income more accurately.

Keywords: Core self-evaluations, implicit personality, acquaintance reports, job performance, income 
Personality's relationships with work criteria has been studied extensively (Barrick, Mount, \& Judge, 2001), and core self-evaluations (CSE) has emerged as an important predictor of work outcomes. CSE is a meta-trait that includes four lower trait dimensions, namely, locus of control, emotional stability, self-efficacy, and self-esteem, and it has been shown to be similarly important as conscientiousness to job performance prediction (Bono \& Judge, 2003). In addition, research has demonstrated that CSE predicts other important work criteria, such as commitment, (lower) work stress, and career success (Chang et al., 2012; Judge, 2009).

Although these findings for CSE are impressive, they are based upon explicit selfreport measures of CSE, which could have some limitations, such as potentially inaccurate responses due to faking, socially desirable self-presentation, and self-deception (Morgeson et al., 2007; Greenwald et al., 2009; Barrick \& Mount, 1996). For instance, when asked about CSE, some employees might report that they are very confident and optimistic only after they have reflected on their perceptions of their personality and on the social desirability of those perceptions. These limitations suggest that scholars and practitioners may be missing elements of CSE when relying exclusively on explicit self-report measures (De Cuyper et al., 2017; Morgeson et al., 2007; Uhlmann et al., 2012). When put into practice, an incomplete or less accurate understanding of CSE might result in poorer outcomes for organizations, such as if a person were promoted into a leadership role due to faking higher optimism and confidence on a questionnaire.

Although a step in the right direction, the response to this situation should not be merely to obtain more accurate estimates of explicit personality (e.g., through other-ratings), but to also assess aspects of personality that are less influenced by deliberative cognition, namely, implicit personality (Back, Schmukle, \& Egloff, 2009; Greenwald \& Farnham, 2000). As illustrated above, explicit personality is deliberative and reflective, resulting from 
individual differences in propositional representations of the self (Back et al., 2009). Explicit personality is formed by conscious information processing and intentional reasoning. On the other hand, implicit personality is intuitive and reflexive, and is the product of individual differences in associative representations of the self (Back et al., 2009). Implicit personality is created by automatic (nonconscious) processing and behaviour that is informed by numerous past experiences, and it is uninfluenced by conscious deliberation and reflection (Lieberman, 2007; Meglino \& Korsgaard, 2007). Thus, in contrast to the above example of explicit CSE, that individual's implicit CSE might differ (e.g., "not very confident nor optimistic"), not only due to inaccurate self-reporting, but because implicit CSE is a related but distinct personality construct.

CSE is often characterized as a conscious appraisal (Judge, Erez, Bono, \& Thoresen, 2003), but it also has a subconscious evaluative component that is related to one's beliefs (Judge, Locke et al., 1998; Judge, Locke, \& Durham, 1997; Murphy, 2012). Despite this conceptualization, empirical research has yet to examine implicit CSE, and, therefore, we believe a measure of implicit CSE should be developed. Moreover, because implicit and explicit personality has been shown to be, at least in part, mutually independent predictors of (work) behaviour (Asendorpf et al., 2002; Dietl et al., 2017; Greenwald, Poehlman, Uhlmann, \& Banaji, 2009; James et al., 2005; Johnson et al., 2012; Leavitt, Fong, \& Greenwald, 2011), using both types of CSE measures could provide a more complete picture of employee behaviour, job performance, and career success. Put differently, by neglecting the implicit aspects of CSE, scholarly understanding is incomplete and we may underestimate the (overall) influence of CSE on employee behaviour.

Therefore, we seek to investigate both explicit and implicit CSE's relationships with important work outcomes, namely, task performance, organizational citizenship behaviours (OCB), and income. Our aim is not to replace explicit, self-report measures of CSE in the 
literature, but to present a complementary implicit measure that contributes to a more complete picture of CSE in the workplace. Based on theoretical and empirical implicit personality research (Back et al., 2009; Johnson, Tolentino, Rodopman, \& Cho, 2010), we developed and pilot tested a measure of implicit CSE, and, subsequently, assessed if implicit CSE incrementally predicts job performance, organizational citizenship behaviours (OCB), and income beyond explicit and other-rated CSE.

Our research offers three key contributions. First, although theoretical and empirical studies suggest that CSE operates at explicit and implicit levels (De Cuyper et al., 2017; Greenwald \& Farnham, 2000; Judge, Locke et al., 1998; Judge et al., 1997), organizational research has exclusively focused on explicit CSE. Therefore, our study heeds the calls that research focus on alternatives to explicit measurement and advance implicit assessment of personality (Morgeson et al., 2007; Sackett, Lievens, Van Iddekinge, \& Kuncel, 2017). By assessing CSE using both explicit and implicit measures, we are able to develop a more complete understanding of CSE, an important predictor of work outcomes.

Second, functional magnetic resonance imaging (fMRI) has shown that explicit cognitions (e.g., explicit self-rated CSE) are processed in brain regions related to executive control and deliberation (Lieberman, 2007). Consequently, explicit self-reports (e.g., questionnaires) rely on individual self-awareness and are open to social desirability and selfpresentation biases (Perugini \& Banse, 2007; Wilson \& Dunn, 2004). Whereas, implicit associations (e.g., implicit CSE) are processed in regions linked to automatic somatic and affective systems, and empirical research indicates that implicit personality is less open to the weaknesses of explicit self-reports (Greenwald et al., 2009; Vecchione et al., 2014). Thus, our research on implicit CSE investigates a construct that could be robust to many of the problems faced by explicit self-reports (e.g., faking and self-deception). 
Third, since there is a consensus that observer-reports of personality have meaningful predictive validity (Connelly \& Ones, 2010), we additionally tested the validity of the implicit CSE measure by assessing if it would predict criteria beyond not only explicit selfratings, but also acquaintance CSE reports. As indicated by the Trait-Reputation-Identity Model (McAbee \& Connelly, 2016), which draws on the logic of the Johari window (Luft \& Ingham, 1955), explicit self- and observer-ratings can provide CSE information that is known to the self and/or others. However, we argue that, since implicit CSE is unknown to both self and others, it potentially is able to speak to the fourth quadrant of the Johari Window (i.e., unknown to self and others), thereby highlighting implicit CSE's potential for incremental prediction of outcomes. Thus, by using all three sources of information (i.e., explicit selfreports, reaction time data capturing implicit CSE, and other-ratings; Back et al., 2009) scholars could find a better understanding of CSE and achieve improved prediction of work behaviours and outcomes.

\section{Explicit and Implicit Core Self-Evaluations}

CSE concerns “one's worthiness, effectiveness, and capability as a person” (Judge et al., 2003, p. 304), and numerous studies have related self-reported explicit CSE to various work criteria, such as job performance, OCB, and salary (see Chang, Ferris, Johnson, Rosen, $\&$ Tan, 2012). Accessed via introspection, direct self-report measures of CSE are obtained through controlled, conscious processes. Even though self-reports have shown strong criterion validity and provide several methodological advantages (e.g., high content validity, reliability, and predictive validity; Perugini \& Banse, 2007), they also have some notable shortcomings.

First, while self-reports rely on the reflective capacity of individuals and their selfknowledge, the nonconscious processes involved in personality, attitudes, and self-esteem are inaccessible to introspection (Wilson \& Dunn, 2004). Second, people tend to construct 
beneficial personal narratives using only their conscious mental processes (Wilson \& Dunn, 2004), thus limiting the value of self-reports. Third, self-reports are vulnerable to social desirability and self-presentation (Perugini \& Banse, 2007). In particular, in evaluative situations (e.g., high-stakes testing, job interviews), individuals present themselves more favourably in order to attain valued rewards (Greenwald et al., 2009). For instance, manager self-reports have been found to be overestimated and discrepant from observer ratings (Gentry, Hannum, Ekelund, \& De Jong, 2007).

Consequently, scholars have concluded that, in order to understand and predict personality-related behaviour more completely, direct self-report measures must be complemented by other approaches to personality measurement such as indirect measures (Back et al., 2009; De Cuyper et al., 2017; Johnson et al., 2009). Although many have assessed personality via other-reports (Oh, Wang, \& Mount, 2011), which may provide additional incremental validity beyond explicit self-reporting, such assessment is open to at least some of these same limitations (e.g., inadequate other-knowledge and using only consciously processed information). Thus, some researchers have investigated indirect, implicit personality measurement, which should not suffer from these concerns (Back et al., 2009; Greenwald \& Banaji, 1995; Greenwald \& Farnham, 2000).

Personality has both explicit and implicit elements, suggesting a dual process (i.e., reflective and impulsive) model of behaviour regulation (Back et al., 2009; De Cuyper et al., 2017; Strack \& Deutsch, 2004). Thus, personality-related behaviours result from both deliberate/reflective information processing and from automatic/impulsive information processing, which, respectively, result in explicit and implicit personality (Back et al., 2009; Strack \& Deutsch, 2004). On the one hand, explicit personality corresponds to differences between individuals in how they categorize situations, which actions they prefer, and how they deliberately act on these inclinations (Schnabel, Asendorpf, \& Greenwald, 2008). As the 
explicit self-concept is shaped by deliberate/controlled information processing, individuals can accept its content as true or reject it as false. This, for example, enables individuals to modify their responses (e.g., to self-report questionnaires) due to self-presentational concerns (e.g., during a selection procedure).

On the other hand, implicit personality is shaped by repeated automatic activation of the self-concept (e.g., "I am competent"), where both situational cues (e.g., a colleague asks for assistance with a task problem) and motivational tendencies (e.g., approaching) lead to spontaneous behaviour (e.g., solving task problem). This behaviour, in turn, activates the trait concept (e.g., competence). Repeated activation of this chain culminates in strong implicit associations between the self and the respective trait attribute (e.g., being competent). The stronger the relation, the faster situational cues can trigger the activation of this implicit selfconcept (Schnabel \& Asendorpf, 2010). Scholars argue that these personality-related selfrepresentations, triggered in automatic information processing, correspond to the implicit self-concept of personality (Asendorpf et al., 2002; De Cuyper et al., 2017).

Since CSE and its components lie, at least in part, outside of conscious awareness (Judge et al., 1997), implicit CSE should be investigated. Specifically, Judge et al. (1998) described CSE as stemming from "the fundamental, subconscious conclusions individuals reach..." (p. 18), indicating that it has aspects which operate outside of awareness (see also Judge et al., 2007). Moreover, research on implicit social cognition demonstrates that two core components of CSE, self-esteem and emotional stability, have both explicit and implicit elements, supporting the construct validity of the implicit self-concept of personality (Back et al., 2009; De Cuyper et al., 2017; Greenwald \& Farnham, 2000; Grumm \& von Collani, 2007). Consequently, in line with previous dual process models in the domain of self-esteem and personality (Back et al., 2009; De Cuyper et al., 2017; Greenwald \& Farnham, 2000), we conceptualize implicit CSE similar to its explicit counterpart, but as a more basic and 
enduring automatic attitude towards the self, being more affective and impulsive, rather than cognitive and deliberative.

We argue that, although both implicit and explicit CSE will lead to higher job performance and income, implicit CSE will predict job performance and income beyond explicit CSE. CSE is thought to influence income and job performance via its effects on motivation (Judge \& Hurst, 2007). Conceptually, we contend that implicit CSE is closely tied to automatic approach/avoidance motivation, persistence, and subconscious goal setting (Back et al., 2009; Dijksterhuis \& Aarts, 2010; Elliot \& Trash, 2002; Ferris et al., 2011). Whereas, explicit CSE is related to self-reported motivation and deliberate goal setting. Thus, the deeper motivational roots of implicit CSE should allow for discriminate prediction of CSE-related behaviours. In addition, Ferris et al. (2011) proposed and found that high CSE individuals achieve greater job performance because they are more likely to adopt approach motivation orientations and less likely to have avoidance orientations. Given the importance of these same approach/avoidance motivational tendencies to implicit personality (Back et al., 2009), these findings suggest that implicit CSE should be highly relevant to work behaviours. Empirical research supports these assertions, because implicit personality has predicted work criteria, such as job performance, $\mathrm{OCB}$, and co-worker personality perceptions, with a combination of implicit and explicit measures providing the best predictive validity (Dietl et al., 2017; Leavitt et al., 2011; Johnson et al., 2010). Importantly, implicit measures of trait affectivity and neuroticism, an implicit form of an aspect of CSE, have predicted behaviour (Back et al., 2009; Steffens \& Schulze-König, 2006) and work outcomes above and beyond direct measurement (e.g., job performance; Johnson et al., 2010; Vecchione et al., 2016).

Job performance contains both in-role (task) and non-task elements (e.g., OCB), and we follow this classification by using both aspects of job performance as criteria (Rotundo \& 
Sackett, 2002), in addition to income, a measure of career success (Heslin, 2005). Therefore, building on research linking CSE with task performance, $\mathrm{OCB}$, career success, and salary (e.g., Chang et al., 2012; Dietl, Rule, \& Blickle, 2018; O’Neill, McLarnon, Xiu, \& Law, 2016), and supporting the implicit characteristics of CSE, we hypothesize:

Hypothesis 1: Implicit CSE positively relates to a) task performance, b) OCB, and c) income.

Hypothesis 2: Implicit CSE positively predicts a) task performance, b) OCB, and c) income above and beyond explicit self-ratings of target CSE.

\section{Observer Ratings of Core Self-Evaluations}

Implicit CSE could be additionally validated if it still predicts work outcomes when utilizing both explicit self-ratings and other-ratings of CSE. Given that implicit CSE differs in both the source of information (i.e., self vs. other) and the method (i.e., implicit vs. explicit) from other-rated CSE, we expect that it incrementally predicts work outcomes beyond other-rated CSE. Moreover, scholars called for studies to examine implicit, explicit, and other-rated personality because, by using all three sources of personality information, a better understanding of personality and behaviour prediction could result (Back et al., 2009). As indicated by the Trait-Reputation-Identity (TRI) Model (McAbee \& Connelly, 2016), which is based on the Johari Window (Luft \& Ingham, 1955), explicit self-rated personality is reflected in one's trait (i.e., known to the self and others) and identity (i.e., known to the self, but unknown to others), and observer-ratings of personality indicate a target's trait (i.e., known to target and others) and reputation (i.e., unknown to target, but known to others). Extending the TRI Model, we contend that implicit personality taps into a unique element of the Johari Window (Luft \& Ingham, 1955) not covered by explicit self-ratings nor otherratings: unknown (i.e., what is not perceived by self and by others). Since CSE pertains to one's internal self-beliefs that are difficult to access or observe (Murphy, 2012; Vazire, 
2010), we believe that implicit CSE will incrementally predict job performance and income beyond explicit self-reported and other-reported CSE. We hypothesize:

Hypothesis 3: Implicit CSE positively predicts a) task performance, b) OCB, and c) income above and beyond explicit self-ratings and other-ratings of target CSE.

First, we conducted Study 1 to assess the validity of a newly developed CSE Implicit Association Test (IAT), exploring the overlap between implicit and explicit CSE, as well as between implicit CSE and implicit self-esteem. Moreover, we tested if self-ratings of the adjectives we selected for the CSE IAT shared substantial variance with a standard self-report CSE measure to justify the selection of CSE adjectives used for the indirect measure of CSE. In Study 2, we investigated the criterion validity of implicit CSE by assessing the relationships of employee CSE (i.e., implicit, self-rated, and personal acquaintance-rated) with work colleague-rated task performance, $\mathrm{OCB}$, and income.

\section{Study 1}

The aim of Study 1 was to determine the extent of agreement between implicit CSE, self-rated CSE, and an established standard measure of implicit self-esteem (Greenwald \& Farnham, 2000). Typically, explicit self-report measures of personality have low and often nonsignificant correlations with measures of implicit personality (Back et al., 2009; Dietl et al., 2017; Greenwald \& Banaji, 1995; James et al., 2005; McClelland, Koestner, \& Weinberger, 1989; Steffens \& Schulze-König, 2006; Uhlmann et al., 2012; Vecchione, Dentale, Alessandri, \& Barbaranelli, 2014). The likely reason is that self-report and implicit measures assess complementary aspects of personality (Back et al., 2009; Bornstein, 2002; James et al., 2005), but some scholars have noted various additional issues, such as response factors (e.g., evaluation apprehension), introspective limitations, and social desirability pressures (Fazio \& Olson, 2003; Greenwald et al., 2009; Nosek \& Smyth, 2007). Moreover, a valid implicit personality measure should correlate stronger with another valid implicit 
measure assessing a similar personality trait than with an explicit measure of the same personality trait (De Cuyper et al., 2017).

Therefore, if the CSE IAT is valid, implicit CSE and implicit self-esteem should be significantly and positively related, whereas, implicit CSE and self-ratings of CSE should have a low and/or nonsignificant relationship. Also, self-ratings of the CSE IAT items should strongly correlate with a standard self-report inventory of CSE (e.g., CSES; Judge et al., 2003) to justify the selection of the adjectives used for the explicit self-ratings of CSE and the CSE IAT.

\section{Method}

\section{Participants and Procedure}

Eighty-four undergraduates at a German university participated in exchange for course credit. $85.7 \%$ of the undergraduates studied business administration and economics, $13.1 \%$ studied management, and $1.2 \%$ studied other majors. The mean age was 22.9 years $(\mathrm{SD}=1.5)$ and $62(73.8 \%)$ were female. Participants completed an online survey to assess self-rated CSE, and, about one week later, we assessed implicit CSE and self-esteem using Inquisit 4.0.2.0 (2014). Two persons were excluded from analyses due to IAT disqualification criteria ${ }^{1}$. Thus, our final dataset includes 82 participants. All measures were administered in German.

\section{Measures}

Implicit core self-evaluations. Given its nonconscious nature, implicit CSE needs to be indirectly measured, such as with an implicit association test (Back et al., 2009; De

\footnotetext{
${ }^{1}$ Following Greenwald et al. (2003), we excluded those with error rates greater than $30 \%$ in the critical IAT blocks three and five (2 participants), or IAT protocols where more than $10 \%$ of trials had response latency less than 300 milliseconds (2 participants).
} 
Cuyper et al., 2017), which is the most widely used indirect measurement task to assess implicit personality. This measurement task reflects the to-be-measured construct through automatic processes, which are inferred from behavioural reactions in reaction time procedures. Using an indirect (implicit) measure can prevent the instigation of response factors found in self-reports, and it also can collect information that is at least partly outside of awareness (Egloff, Schwerdtfeger, \& Schmukle, 2005). Prior research has shown, that the IAT is a reliable and accepted method to capture implicit personality (Greenwald, McGhee, \& Schwartz, 1998). It is robust to faking attempts, and demonstrates acceptable internal consistency and test-retest reliability (Asendorpf et al., 2002; Greenwald \& Farnham, 2000; Nosek, Greenwald, \& Banaji, 2007).

We selected stimuli (i.e., adjectives) to assess participant implicit CSE that were adapted from Nübold \& Maier (2012). Consistent with the construction of the explicit Core Self-Evaluations Scale (Judge et al., 2003), we ensured that the adjectives not only reflected the content of the CSE subdomains (i.e., emotional stability, self-efficacy, self-esteem, locus of control), but also that they covered the broad domain of CSE. Therefore, we chose items that focused on the commonality among CSE subdomains, or covered one or more of them.

The computer-based CSE IAT requires participants to rapidly sort items by category using a keyboard. In the first block, persons are given words referring to two target categories, $M e$ (I, me, my, self) and Other (other, they, them, their), and asked to correctly categorize them (i.e., press the "x" key when words from category $M e$ appear, and the "m" key when words from category Other appear). The second and fourth blocks involve sorting CSE-related words into two categories, Positive (competent, stable, satisfied, certain, independent, optimistic, confident, valuable) and Negative (incompetent, unstable, dissatisfied, uncertain, dependent, pessimistic, shy, valueless), swapping the key to press for each category between blocks. The third and fifth blocks require participants to use a shared 
response key. In the third block, a word related to the $M e$ or the Positive category requires an "x" key press, whereas, a word related to the Other or the Negative category requires an "m" key press. In the fifth and final block, the pairing reverses (Me or Negative was associated with "x", and Other or Positive was paired with "m"). See Table 1 for further information. Differences in average response latency for the combined critical blocks 3 and 5 constitute the IAT measure (e.g., if associating CSE-related words with words referring to the self takes less reaction time than associating CSE-related words with words referring to other people, it indicates higher implicit CSE). We scored the CSE IAT according to the improved scoring algorithm, "D1", which is commonly used and generally accepted (Greenwald, Nosek, \& Banaji, 2003; Leavitt et al., 2011). The D1 algorithm uses the difference between mean latencies of the two combined tasks from blocks 3 and 5 as the numerator. These means contained error trials (i.e., a trial in which a participant erroneously categorized a stimulus), which had a built-in time penalty, because the participant was obliged to complete each trial with the correct response. Trials with more than 10,000 milliseconds were eliminated. The numerator difference is divided by an inclusive standard deviation computed from all of the participant's latencies in both combined tasks. In addition, as recommended, we excluded participants with error rates greater than $30 \%$ (2 participants) or IAT protocols where more than $10 \%$ of trials had a response latency less than 300 milliseconds ( 2 participants); see also footnote 1. More computational details can be found in Greenwald and colleagues (2003), who demonstrated that the $\mathrm{D}$ algorithm (i.e., each of the six variations D1-D6) is psychometrically better than several alternatives.

The D1 measure and its interpretation are quite similar to the effect-size measure $d$ (Cohen, 1977). Thus, the higher the IAT effect - the strength of association between CSE related adjectives and the self-concept - the higher the estimated implicit CSE. To estimate internal consistency, we calculated the split-half reliability of the $\operatorname{IAT}(\alpha=.71)$. For each 
participant, two separate D1 sub-scores were created by applying the scoring algorithm separately to two mutually exclusive subsets of the IAT's combined-task trials (i.e., two subsets from block 3 and 5). The correlation between these two D1 sub-scores, across participants, provided a measure of internal consistency (i.e., split-half reliability).

Implicit self-esteem. To measure implicit self-esteem, we used a self-esteem IAT (Greenwald \& Farnham, 2000), which has been often used for validation purposes (e.g., Dislich et al., 2012; Schröder-Abé, Rudolph, \& Schütz, 2007), with concept discrimination among four self-relevant (I, me, my, self) and four non-self-relevant (other, they, them, their) words, and attribute discrimination between six pleasant (e.g., sunshine, joy, peace) and six unpleasant (e.g., poison, pain, death) words. The self-esteem IAT consisted of five blocks of trials, and had the same structure and number of trials per block as the CSE IAT. The splithalf reliability of the self-esteem IAT was $\alpha=.62$.

Core self-evaluations. Participants provided CSE self-ratings using the 12-item measure of the German-validated the Core Self-Evaluations Scale (CSES; Judge et al., 2003; Stumpp et al., 2010). The response scale ranges from 1 (strongly disagree) to 5 (strongly agree). A sample item is "When I try, I generally succeed" $(\alpha=.82)$.

Core self-evaluations bipolar scale. Participants also assessed CSE using an 8-item bipolar adjective scale (i.e., competent - incompetent, stable - unstable, satisfied dissatisfied, certain - uncertain, independent - dependent, optimistic - pessimistic, confident shy, valuable - valueless) adapted from Nübold \& Maier (2012). This scale consisted of the 16 adjectives selected for the CSE IAT. The 6-point scale ranges from +3 to -3 with three verbal anchors on each side (very, quite, rather; $\alpha=.87$ ).

\section{Results and Discussion}


As expected, explicit CSE and implicit CSE were statistically independent from each other, $r=-.03, p=.78$ for the bipolar CSE adjectives scale ${ }^{2}$. The correlation size is consistent with studies that found non-significant and low correlations between IAT and explicit personality measures (e.g., Back et al., 2009; Brunstein \& Schmitt, 2004; Dietl et al., 2017; Greenwald et al., 2009; Schröder-Abé et al., 2007; Vecchione et al., 2014). In addition, we found that implicit CSE and implicit self-esteem were moderately correlated $(r=.36, p<$ .01 ), suggesting that implicit CSE should not be equated with implicit self-esteem. The size of this correlation mirrors research that found moderate correlations among different facets of implicit self-esteem (e.g., social and performance self-esteem; Klavina, Schröder-Abe, \& Schütz, 2012). Prior research also has shown that IAT measures of similar but distinct constructs are moderately related (Dislich et al., 2012). Finally, the self-ratings of the eight bipolar CSE IAT adjectives displayed good internal consistency $(\alpha=.87)$, and correlated strongly with Judge et al.'s CSES $(r=.76, p<.01)$. This justifies the selection of the adjectives that we used for both the CSE IAT and the explicit self-ratings of CSE, because we found a high convergent correlation between the bipolar CSE adjective scale and Judge et al.’s established CSES.

\section{Study 2}

In Study 2 we administered the CSE IAT, and explicit self-rating measures of CSE and income to employees. In addition, personal acquaintances rated target employee CSE, and work colleagues provided ratings of task performance and OCB. This study tests Hypotheses 1-3.

\section{Methods}

\footnotetext{
${ }^{2}$ To enable a direct and fair comparison of the predictive validity of both kinds of measures, in Study 2, we used the same descriptive CSE adjectives for both the CSE IAT and for explicit CSE. Therefore, we do not compare implicit CSE with the Judge et al.'s (2003) CSES here.
} 


\section{Sample and Procedure}

A diverse employee sample from various organizations and occupational backgrounds in Germany was recruited by 11 undergraduates, in partial fulfilment of their study requirements. Data collection took place from June 2013 to February 2014. Participants were personally approached and, upon agreement, received an e-mail including a link to a questionnaire. After providing self-reports, employees were asked to nominate, by reporting email-addresses, one personal acquaintance and one work colleague to provide other-ratings of the target employee. Then, employees completed the CSE IAT using Inquisit 4.0.2.0 (2014), as described above. Other-raters were contacted via e-mail. Identification codes allowed matching the three questionnaires per target employee.

Self-ratings were provided by 244 employees and they were assessed by 239 personal acquaintances and 220 work colleagues. Employees who provided self-ratings were not allowed to provide observer ratings for personal acquaintances or colleagues. In total, complete ratings for (a) self, (b) personal acquaintance, (c) work colleague, and (d) CSE IAT reaction time data were available for 158 individuals. Four employees were excluded, due to IAT disqualification criteria ${ }^{3}$. Thus, our final dataset included 154 triads, totalling 462 raters.

$48.1 \%$ of the employees, $59.7 \%$ of the personal acquaintances, and $56.3 \%$ of the colleagues were women. Employees, personal acquaintances, and colleagues had mean ages of $34.8(S D=12.4), 34.8(S D=13.8)$, and $36.3(S D=11.6)$ years, respectively. On average, employees had about 14 years of work experience, and worked in industries such as civil service $(15.6 \%)$, automotive $(13.0 \%)$, healthcare $(7.1 \%)$, education $(6.5 \%)$, trade $(6.5 \%)$, and capital goods sectors (6.5\%). 42.2\% of personal acquaintances were partners or spouses and $26 \%$ were friends, with most of the remainder being other family members. On average,

\footnotetext{
${ }^{3}$ We followed the same IAT disqualification criteria as detailed in Study 1.
} 
acquaintances knew targets for 15.5 years $(S D=12.04)$, and knew them very well $(M=6.62$, $S D=.71$ on a scale from 1 to 7$)$. Colleagues worked with targets an average of 4.34 years $(S D=4.85)$, and knew them well $(M=5.36, S D=1.19)$.

\section{Measures}

Implicit core self-evaluations. Employees completed the same CSE IAT as in Study 1. The split-half reliability was $\alpha=.73$.

Explicit core self-evaluations. To enable a direct and fair comparison of the predictive validity of both kinds of measures, we used the same descriptive CSE adjectives in both the CSE IAT and for measuring explicit CSE. This method is consistent with prior research on implicit individual differences (Asendorpf et al., 2002; Back et al., 2009; Brunstein \& Schmitt, 2004; De Cuyper et al., 2017; Dietl et al., 2017). The only difference between the present study's explicit CSE and CSE IAT measures concerns the method of measurement. Whereas, the commonly-used CSES questionnaire (Judge et al., 2003) differs also from the CSE IAT with respect to the format and the content of the items, and these types of differences reduce the implicit-explicit association (e.g., De Cuyper et al. 2017). Therefore, the comparison and interpretation of the findings of both measures are more straightforward when using the same CSE adjectives in both measures. Self-ratings and personal acquaintance ratings were provided using the same 8-item bipolar adjective scale (i.e., competent - incompetent, stable - unstable, satisfied - dissatisfied, certain - uncertain, independent - dependent, optimistic - pessimistic, confident - shy, valuable - valueless) that was used for Study 1. The Cronbach's $\alpha$ was .83 for self-ratings and .80 for acquaintance ratings.

Organizational Citizenship Behavior. Colleagues rated target OCB using Staufenbiel and Hartz's (2000) well-established measure. The four OCB subscales (i.e., altruism, general 
compliance, sportsmanship, and initiative) were averaged to build a composite score ( $\alpha=$ .85). The scale ranges from 1 (strongly disagree) to 7 (strongly agree).

Task performance. Colleagues rated target task performance using Staufenbiel and Hartz's (2000) scale, constituting the German adaption of Williams and Anderson's (1991) scale, with ranges from 1 (strongly disagree) to 7 (strongly agree). Cronbach's $\alpha$ was .86.

Income. Employees reported their yearly gross income based on their vocational work. Mean income was 40,623 Euro ( $S D=26,191$ Euro).

\section{Results}

Preliminary analyses. We conducted confirmatory factor analyses to assess the discriminant validity of our direct measures. We followed Williams and O'Boyle's (2008) recommendations and created three to four item parcels as composite indicators for each construct, to achieve an optimal ratio of sample size to number of estimated indicators (e.g., Sun \& Van Emmerik, 2015). In addition, parcelled data have higher communality, reliability, and are less likely to violate distributional assumptions than item-level data (Little, Cunningham, Shahar, \& Widaman, 2002). For the multidimensional construct OCB, we used the domain-representative approach to create four parcels (i.e., by combining items from across facets), and for the unidimensional construct task performance we employed the itemto-construct balance approach to create three parcels (Williams \& O’Boyle, 2008). Because the CSE bipolar adjective scale directly measures CSE (and not its subcomponents), we used the item-to-construct balance approach to create three parcels each for explicit and acquaintance-rated CSE.

Prior to confirmatory factor analyses, we examined the distributions of items and parcels. Kurtosis that is not between -7 and +7 and skewness that is not between -2 and +2 are indicative of non-normal distributions (Curran, West, \& Finch, 1996). Normality indices displayed appropriate levels of univariate skewness and kurtosis for all items and parcels with 
the exception of two task performance items which displayed a kurtosis $>11$ and a skewness $<-2$. Using recommended data screening techniques (DeSimone, Harms \& DeSimone, 2015) we identified one other-rating participant (i.e., who provided strongly inconsistent ratings for similar items) as an outlier. This participant was subsequently deleted, resulting in a sample of 153 triads for the final analyses. After removing this participant, all items showed appropriate levels of univariate skewness and kurtosis.

Therefore, to assess the discriminant validity of our direct measures we proceeded with confirmatory factor analyses using robust maximum likelihood estimation in Mplus 7.3 (Muthén \& Muthén, 2012). Our hypothesized four-factor model (i.e., explicit CSE, acquaintance-rated CSE, task performance, and OCB) showed very good fit to the observed covariance matrix $\left(\chi^{2}(59, N=153)=85.63, p=.01 ; \chi^{2} / d f=1.45, \mathrm{CFI}=.98, \mathrm{TLI}=.96\right.$, $\mathrm{RMSEA}=.05, \mathrm{SRMR}=.05$ ), with significant factor loadings for all parcels. The four-factor measurement model produced a significant improvement in chi-square over more parsimonious three-factor models in which we combined the parcels of the following constructs to load on the same factor: explicit CSE and acquaintance-rated $\operatorname{CSE}\left(\Delta \chi^{2}(3)=\right.$ 157.89, $p<.001)$; explicit CSE and task performance $\left(\Delta \chi^{2}(3)=286.20, p<.001\right)$; explicit $\operatorname{CSE}$ and $\mathrm{OCB}\left(\Delta \chi^{2}(3)=168.20, p<.001\right)$; task performance and $\mathrm{OCB}\left(\Delta \chi^{2}(3)=56.853, p<\right.$ $.001)$; acquaintance-rated CSE and task performance $\left(\Delta \chi^{2}(3)=292.34, p<.001\right)$; acquaintance-rated CSE and $\mathrm{OCB}\left(\Delta \chi^{2}(3)=175.34, p<.001\right)$; task performance and OCB $\left(\Delta \chi^{2}(3)=56.853, p<.001\right)$.

Self-rated explicit and implicit CSE exhibited a low association that did not reach conventional levels of significance $(r=.13, p=.10$; see Table 2). Moreover, explicit CSE was positively related to $\mathrm{OCB}(r=.20, p<.05 ; 95 \%$ CI $[.05 ; .35])$, but unrelated to task performance $(r=.11, p=.19 ; 95 \%$ CI $[-.05 ; .26])$ and income $(r=.06, p=.45 ; 95 \%$ CI [-.10; .22]). We return to these findings in the Discussion section. 
Hypothesis Testing. Hypothesis 1 predicted that implicit CSE will positively relate to a) task performance b) OCB, and c) income. Consistent with $\mathrm{H} 1 \mathrm{~b}$ and $\mathrm{H} 1 \mathrm{c}$, implicit CSE positively related to $\mathrm{OCB}(r=.23, p<.01)$ and income $(r=.18, p<.05$; see Table 2$)$. However, although the association between implicit CSE and task performance was positive, it was only marginally significant $(r=.15, p=.07)$. Therefore, H1a was partially supported. Hypothesis 2 postulated that implicit CSE will positively predict a) task performance, b) OCB, and c) income beyond explicit self-rated CSE. As seen in Table 3 (Step 2a), implicit CSE predicted OCB $(b=.40, p<.05,4.0 \%$ additional variance explained $)$ and income $(b=$ $14735.45, p<.05,3.2 \%$ additional variance explained) beyond explicit CSE, supporting H2b and H2c. Yet, implicit CSE did not incrementally predict task performance $(b=.25, p=.102$, $1.7 \%$ additional variance explained). Thus, $\mathrm{H} 2 \mathrm{a}$ was not supported. In support of Hypothesis $3 \mathrm{~b}$ and $3 \mathrm{c}$, implicit CSE predicted OCB $(b=.38, p<.05,3.6 \%$ additional variance explained, Table 3, Step 3) and income ( $b=13678.26, p<.05,2.7 \%$ additional variance explained $)$ beyond both explicit self-rated and acquaintance-rated CSE. Again, implicit CSE did not incrementally predict task performance beyond explicit self-rated and acquaintance-rated CSE. Hence, H3a was not supported.

We also examined whether implicit CSE incrementally predicts the outcomes beyond only acquaintance-rated CSE. As seen in Table 3, Step 2b, implicit CSE again incrementally predicted OCB $(b=.41, p<.01,4.2 \%$ additional variance explained $)$ and income $(b=$ 13503.50, $p<.05,2.7 \%$ additional variance explained). Furthermore, implicit CSE incrementally predicted task performance $(b=.25, p=.09,1.8 \%$ additional variance explained) beyond acquaintance-rated CSE only when applying a one-tailed test.

Supplemental Analyses of Acquaintance-rated CSE. We exploratorily examined if personal acquaintance-rated CSE predicted task performance, $\mathrm{OCB}$, and income incrementally beyond self-rated CSE. Personal acquaintance ratings significantly predicted 
OCB $(b=.19, p<.05,2.7 \%$ additional variance explained; Table 3, Step $2 \mathrm{c})$ and income $(b=$ 9821.93, $p<.05,4.1 \%$ additional variance explained) beyond self-rated CSE, but not task performance. Moreover, when including all other predictors (Table 3, Step 3) personal acquaintance-rated CSE predicted only income $(b=9286.12, p<.05)$, but not OCB nor task performance.

\section{Discussion}

In Study 2 we found that implicit CSE was positively associated to OCB and income. It is noteworthy that implicit CSE predicted these outcomes above and beyond explicit selfrated and acquaintance-rated CSE.

Moreover, as expected, explicit and implicit CSE revealed a small and non-significant association. The correlation size is consistent with many studies that found non-significant and small correlations between IAT and explicit personality measures (Back et al., 2009; Brunstein \& Schmitt, 2004; Dietl et al., 2017; Greenwald et al., 2009; Schröder-Abé et al., 2007; Vecchione et al., 2014). We also tested the possibility that the weak non-significant association is at least partly due to an inadequate power to test small effect sizes. Therefore, we calculated the correlation between implicit and explicit CSE, without removing individuals with missing data for coworkers and acquaintances, and found a small significant correlation, $r(242)=.15, p=.02$.

In addition, we found that explicit CSE was positively related to OCB $(r=.20, p<$ $.05 ; 95 \%$ CI $[.05 ; .35])$, but unrelated to task performance $(r=.11, p=.19 ; 95 \%$ CI [-.05; $.26])$ and income $(r=.06, p=.45 ; 95 \%$ CI $[-.10 ; .22])$. The present correlations for explicit CSE with work criteria are somewhat lower than in other studies, but their confidence intervals overlap with the confidence intervals of meta-analytic estimates for other-rated task performance $(r=.13$; lower bound $95 \% \mathrm{CI}=.09)$ and $\mathrm{OCB}(r=.13$; lower bound $95 \% \mathrm{CI}=$ $.08)$, but not income ( $r=.28$; lower bound $95 \% \mathrm{CI}=.26$; Chang et al., 2012). However, a 
recent nationally representative study also found little evidence that higher explicit CSE was related to higher income (Williams \& Gardiner, 2018).

\section{General Discussion}

First, we developed and validated an implicit CSE measure (Study 1). Second, in Study 2, implicit CSE was positively related to OCB and income. Importantly, implicit CSE predicted these outcomes beyond explicit self-rated and other-rated CSE. Overall, the results demonstrated the validity of the implicit CSE measure and its value for predicting work outcomes.

\section{Theoretical Implications}

Implicit features have been shown to be a valuable addition to our understanding of personality and to the prediction of work outcomes (De Cuyper et al., 2017; Dietl et al., 2017; Johnson et al., 2009; Leavitt et al., 2011). The present study extends the implicit personality literature by focusing on an important, but, so far, overlooked aspect of implicit personality: implicit CSE. Scholars have argued that CSE has subconscious elements (Judge, Locke et al., $1997 ; 1998)$, but, prior to the present study, measurement instruments were unable to assess this implicit content. This is a substantive theoretical concern, because a failure to measure implicit CSE creates a disconnection between theory and methods (Uhlmann et al., 2012). Consequently, by developing and validating an indirect measure of implicit CSE, we make a significant contribution to CSE research.

Moreover, the present study answers recent calls from scholars to investigate alternatives to explicit measurement and advance implicit assessment of personality (Sackett et al., 2017). We found that implicit CSE had incremental validity for the prediction of income and OCB above and beyond explicit self-ratings, suggesting that, if using only explicit ratings, scholars potentially underestimate the true effects of CSE on criteria. Building on and extending previous implicit personality research (Back et al., 2009), the 
present findings suggest that implicit CSE taps into the associatively structured aspects of the self and co-produces work behaviour in concert with the reflective aspects of explicit CSE.

We also found that acquaintance ratings of CSE predicted OCB and income beyond self-rated CSE. When also including implicit CSE, the relationship of other-reported CSE with OCB was reduced to marginal significance, but the association of acquaintance-rated CSE with income remained significant. Therefore, it could be that other-reported CSE is especially meaningful for predicting personality's more distal criteria (e.g., income). Taken together, an implication of our study is that, by investigating all three sources of personality information (e.g., explicit, implicit, and other-rated CSE) important work criteria could be predicted more accurately.

Moreover, the present findings provide an interesting contribution to the recently developed Trait-Reputation-Identity Model (McAbee \& Connelly, 2016). This model builds on the Johari Window (Luft \& Ingham, 1955) and focuses on trait information provided by observers and self-respondents, and their shared and distinctive variance components. It investigates which trait information is "known" to either or both the self and others. We extend this model by arguing and finding that implicit CSE reflects an aspect of CSE that is unknown to both self and others, but, nevertheless, is an important predictor of work outcomes such as OCB and income. The extension of this model to include personality information that is not known to self nor to observers is a key theoretical contribution of the present study.

Interestingly, in our research, task performance was not predicted by any of our three CSE measures. While the interpretation of null effects needs to be done cautiously, we will discuss some possible explanations. First, the credibility interval with task performance in a CSE meta-analysis included zero (Chang et al., 2012), indicating that variance in effect sizes across studies could be the result of between-study moderators (e.g., publication status and 
CSE measure used). Second, all three of our CSE measures had (non-significant) small, but positive relations with task performance (i.e., $r=.10$ to .15 ), and implicit CSE had a significant association with task performance when using a one-tailed test. Thus, our sample size may have been not large enough to detect such small effect sizes. A third possibility is that our results for task performance might be attenuated in this sample due to ceiling effects: The task performance scale ranged from 1 to 7 , with the mean rating being 6.21 (i.e., close to the maximum).

\section{Strength, Limitations and Future Research}

A strength of our study is that we used a recommended method for assessing implicit personality (i.e., IAT, De Cuyper et al., 2017). Moreover, we gathered data from four different sources: target employee, coworker, and personal acquaintance questionnaires, as well as employee reaction time data, mitigating potential common method variance bias. In addition, we sampled employees from a range of organizations and occupations, thereby, improving our findings generalizability. Some scholars have lamented that IATs in the domain of attitudes are poor predictors of behaviour and that IAT studies often rely on small samples, challenging future IAT research to empirically demonstrate whether IAT effects found in laboratories translate into "real-world" effects (Oswald, Mitchell, Blanton, Jaccard, \& Tetlock, 2013; 2015). In the domain of implicit personality, we have shown with a relatively large sample of employees that implicit CSE measured via an IAT does predict relevant work behaviours in a field setting, highlighting the usefulness of IAT measurement.

Regarding limitations, due to our field study design, conclusions about causality cannot be made. Thus, future research should use complementary methods, such as longitudinal and experimental studies. Moreover, as noted above, it is possible that our results concerning task performance might have been diminished due to ceiling effects. In addition, consistent with prior studies (e.g., Back et al., 2009; Brunstein \& Schmitt, 2004; 
Greenwald et al., 2009; Schröder-Abé et al., 2007), we found non-significant and low correlations between implicit CSE and explicit CSE. Although this is a typical finding in the domain of implicit and explicit personality, the relationship could be affected by moderators such as the spontaneity of self-reports, meditation, evaluative strength, or self-presentation concerns (Hofmann et al., 2005; Koole, Govorun, Cheng, \& Gallucci, 2009; Nosek, 2005). Future studies could test some of these moderating variables by, for example, examining whether instructing participants to rely on their gut reactions and to respond quickly when providing self-reports enhances the CSE implicit-explicit correlation. In addition, since meditation has been found to promote congruence (i.e., a higher implicit-explicit relationship) between implicit and explicit self-esteem (Koole et al., 2009), this also could be investigated in CSE research.

Moreover, constructs such as impulsivity or self-awareness could change the relationships that implicit traits (Back et al., 2009) or CSE have with work outcomes. For example, research could investigate if the positive relationship between implicit CSE and OCB is stronger for the highly impulsive. Additionally, future studies could assess the implicit aspects of other constructs related to the self-concept, such as implicit performance self-esteem and social self-esteem (Klavina et al., 2012), to develop a more complete picture of how an individual's self-concept influences work outcomes. For instance, we expect that implicit performance self-esteem would relate to task performance, whereas, implicit social self-esteem would predict contextual performance.

Another interesting future research avenue is in the area of implicit CSE and leadership. Managerial self-reports in 360-degree instruments have been found to be exaggerated (Gentry et al., 2007), and many scholars have detailed the problems of leader hubris and inflated sense of self-confidence (e.g. Hiller \& Hambrick, 2005; Judge, Piccolo, \& Kosalka, 2009). Thus, indirect measures assessing a leader's implicit CSE (e.g., IAT) or self- 
concept may be particularly useful. For example, a combination of explicit and implicit CSE may better predict positive leadership behaviours such as transformational and authentic leadership, thereby, extending existing research on leader CSE (Hu, Wang, Liden \& Sun, 2012). Lastly, research has found that the discrepancies between implicit and explicit selfesteem were related to increased nervousness, anger suppression, and impaired health (Schröder-Abe et al., 2007). Future studies could extend this work and examine whether discrepant implicit and explicit CSE relate to poor outcomes for employees, such as increased stress and decreased well-being.

\section{Practical Implications}

In practice, our results suggest that organizations should consider not only an individual's explicit and other-rated CSE, but also the person's implicit CSE, since these three are not strongly related. This could be helpful at the selection stage, where organizations might otherwise rely on self-reported and/or interviewer-evaluated CSE. Organizations desiring to select high CSE individuals might unintentionally not select and/or not promote persons who, of the three, are high on only implicit CSE. In addition, although research has found that individuals can intentionally inflate explicit personality ratings, initial research indicates that this may not be the case with implicit measures such as IATs (Asendorpf et al., 2002; Vecchione et al., 2014). Thus, by employing an implicit measure of CSE, organizations might be able to improve their selection procedures by having noninflated implicit personality data, in addition to the (potentially) inflated self-report measure.

Also, implicit CSE could be useful when organizations are considering personnel promotion. As an employee's tenure increases, it is likely that the individual's understanding of what is socially desirable both within the profession and the organization and how to behave within that culture also strengthens. Certainly, as measured via explicit self-reports, such knowledge and behaviour could be valuable components of job competence and 
performance. However, employees also would have an opportunity to manipulate responses to explicit measures (e.g., CSE). Thus, as the employee's organizational and professional tenure grows, it could be increasingly beneficial to use indirect measures (e.g., CSE IAT), as well as other-reports. Moreover, organizations could use IATs along with 360-degree multirater instruments for employee assessment and development. For instance, measuring implicit CSE may help to clarify discrepancies between employee self-reports and other-ratings, and could potentially assist employees to gain more accurate self-knowledge.

As suggested in regards to employee promotion, it is possible that explicit and implicit CSE assessment could yield different results. Since CSE reflects difficult to access internal self-beliefs (Murphy, 2012), employees may lack self-awareness of their dispositional tendencies on CSE (Haines \& Sumner, 2006), and, thus, would be less likely to generate an accurate explicit self-report. Given the value of CSE to work outcomes, organizational decision makers should consider utilizing other methods of measuring CSE, and additionally examine CSE-relevant behaviour in, for example, interviews (e.g., behavioural questions) and assessment centres. Moreover, implicit CSE could further augment the understanding of an employee's CSE, providing an additional source of CSE-relevant information beyond observer ratings. Consequently, the results of our study suggest that, whenever CSE is assessed by organizations, outcomes for both organizations (e.g., selection and promotion) and individuals (e.g., work performance and career success) could be improved by using all three sources of CSE information. 


\section{References}

Asendorpf, J. B., Banse, R., \& Mücke, D. (2002). Double dissociation between implicit and explicit personality self-concept: The case of shy behavior. Journal of Personality and Social Psychology, 83, 380-393. https://doi.org/10.1037/0022-3514.83.2.380

Back, M. D., Schmukle, S. C., \& Egloff, B. (2009). Predicting actual behavior from the explicit and implicit self-concept of personality. Journal of Personality and Social Psychology, 97, 533-548. https://doi.org/10.1037/a0016229

Barrick, M. R., \& Mount, M. K. (1996). Effects of impression management and selfdeception on the predictive validity of personality constructs. Journal of Applied Psychology, 81, 261-272. https://doi.org/10.1037/0021-9010.81.3.261

Barrick, M. R., Mount, M. K., \& Judge, T. A. (2001). Personality and performance at the beginning of the new millennium: What do we know and where do we go next? International Journal of Selection and Assessment, 9, 9-30.

https://doi.org/10.1111/1468-2389.00160

Bono, J.E., \& Judge, T.A. (2003). Core Self-Evaluations: A review of the trait and its role in job satisfaction and job performance. European Journal of Personality, 17, 5-18. https://doi.org/10.1002/per.481

Bowling, N. A., \& Johnson, R. E. (2013). Measuring implicit content and processes at work: A new frontier within the organizational sciences. Human Resource Management Review, 23, 203-204. https://doi.org/10.1016/j.hrmr.2012.12.001

Brunstein, J. C., \& Schmitt, C. H. (2004). Assessing individual differences in achievement motivation with the Implicit Association Test. Journal of Research in Personality, 38, 536 - 555. https://doi.org/10.1016/j.jrp.2004.01.003 
Chang, C.H., Ferris, D.L., Johnson, R.E., Rosen, C.C., \& Tan, J.A. (2012). Core selfevaluations: A review and evaluation of the literature. Journal of Management, 38, 81-128. https://doi.org/10.1177/0149206311419661

Cohen, J. (1977). Statistical power analysis for the behavioral sciences (Rev. ed.). New York, NY: Academic Press.

Connelly, B. S., \& Hülsheger, U.R. (2012). A narrower scope or a clearer lens for personality? Examining sources of observers' advantages over self-reports for predicting performance. Journal of Personality, 80, 603-641. https://doi.org/10.1111/j.1467-6494.2011.00744.x

Curran, P. J., West, S. G., \& Finch, J. F. (1996). The robustness of test statistics to nonnormality and specification error in confirmatory factor analysis. Psychological Methods, 1, 16-29. https://doi.org/10.1037/1082-989X.1.1.16

De Cuyper K., De Houwer J., Vansteelandt K., Perugini M., Pieters G., Claes L., \& Hermans D. (2017). Using indirect measurement tasks to assess the self-concept of personality: A systematic review and meta-analyses. European Journal of Personality, 31, 8-41. http://dx.doi.org/10.1002/per.2092

DeSimone, J. A., Harms, P. D., \& DeSimone, A. J. (2015). Best practice recommendations for data screening. Journal of Organizational Behavior, 36, 171-181. https://doi.org/10.1002/job.1962

Dietl, E., Meurs, J. A., \& Blickle, G. (2017). Do they know how hard I work? Investigating how implicit/explicit achievement orientation, reputation, and political skill affect occupational status. European Journal of Work and Organizational Psychology, 26, 120-132. http://dx.doi.org/10.1080/1359432X.2016.1225040

Dietl, E., Rule, N. O, \& Blickle, G. (2018). Core self-evaluations mediate the association between leaders' facial appearance and their professional success: Adult's and 
children's perceptions. The Leadership Quarterly, 29, 476-488. https://doi.org/10.1016/j.leaqua.2018.01.002

Dijksterhuis, A., \& Aarts, H. (2010). Goals, attention, and (un)consciousness. Annual Review of Psychology, 61, 467-490. http://dx.doi.org/10.1146/annurev.psych.093008.100445

Dislich, F. X. R., Imhoff, R., Banse, R., Altstötter-Gleich, C., Zinkernagel, A., \& Schmitt, M. (2012). Discrepancies between implicit and explicit self-concepts of intelligence predict performance on tests of intelligence. European Journal of Personality, 26, 212-202. https://doi.org/10.1002/per.827

Egloff, B., Schwerdtfeger, A., \& Schmukle, S.C. (2005). Temporal stability of the Implicit Association Test-Anxiety. Journal of Personality Assessment, 84, 82-88. https://doi.org/10.1207/s15327752jpa8401_14

Elliot, A. J., \& Trash, T. M. (2002). Approach-avoidance motivation in personality: Approach and avoidance temperaments and goals. Journal of Personality and Social Psychology, 82, 804-818. http://dx.doi.org/10.1037/0022-3514.82.5.804

Erez, A., \& Judge, T. A. (2001). Relationship of core self-evaluations to goal setting, motivation, and performance. Journal of Applied Psychology, 86, 1270-1279. http://dx.doi.org/10.1037/0021-9010.86.6.1270

Fazio, R., \& Olson, M. (2003). Implicit measures in social cognition research: Their meaning and use. Annual Review of Psychology, 54, 297-327. https://doi.org/10.1146/annurev.psych.54.101601.145225

Ferris, D. L., Rosen, C. C., Johnson, R. E., Brown, D. J., Risavy, S., \& Heller, D. (2011). Approach or avoidance (or both?): Integrating core self-evaluations within an approach / avoidance framework. Personnel Psychology, 64, 137-161. https://doi.org/10.1111/j.1744-6570.2010.01204.x 
Gentry, W. A., Hannum, K. M., Ekelund, B. Z., \& De Jong, A. (2007). A study of the discrepancy between self- and observer-ratings on managerial derailment characteristics of European managers. European Journal of Work and Organizational Psychology, 16, 295-325. https://doi.org/10.1080/13594320701394188

Greenwald, A. G., \& Banaji, M. R. (1995). Implicit social cognition: Attitudes, self-esteem, and stereotypes. Psychological Review, 102, 4-27. https://doi.org/10.1037/0033$\underline{295 X .102 .1 .4}$

Greenwald, A. G., \& Farnham, S. D. (2000). Using the Implicit Association Test to measure self-esteem and self-concept. Journal of Personality and Social Psychology, 79, 10221038. https://doi.org/10.1037/0022-3514.79.6.1022

Greenwald, A. G., McGhee, D., \& Schwartz, J. (1998). Measuring individual differences in implicit cognition: The Implicit Association Test. Journal of Personality and Social Psychology, 74, 1464-1480. https://doi.org/10.1037/0022-3514.74.6.1464

Greenwald, A. G., Nosek, B. A., \& Banaji, M. R. (2003). Understanding and using the implicit association test: I. An improved scoring algorithm. Journal of Personality and Social Psychology, 85, 197-216. https://doi.org/10.1037/0022-3514.85.2.197

Greenwald, A. G., Poehlman, T. A., Uhlmann, E., \& Banaji, M. R. (2009). Understanding and using the Implicit Association Test: III. Meta-analysis of predictive validity. Journal of Personality and Social Psychology, 97, 17-41. https://doi.org/10.1037/a0015575

Grumm, M., \& von Collani, G. (2007). Measuring big-five personality dimensions with the implicit association test - implicit personality traits or self-esteem? Personality and Individual Differences, 43, 2205-2217. https://doi.org/10.1016/j.paid.2007.06.032 
Haines E.L., \& Sumner K.E. (2006). Implicit measurement of attitudes, stereotypes, and selfconcepts in organizations: Teaching old dogmas new tricks. Organizational Research Methods, 9, 536-553. https://doi.org/10.1177/1094428106286540

Heslin, P. A. (2005). Conceptualizing and evaluating career success. Journal of Organizational Behavior, 26, 113-136. https://doi.org/10.1002/job.270

Hiller, N. J., \& Hambrick, D. C. (2005). Conceptualizing executive hubris: The role of (hyper-) core self-evaluations in strategic decision-making. Strategic Management Journal, 26, 297-319. https://doi.org/10.1002/smj.455

Hofmann, W., Gawronski, B., Gschwendner, T., Le, H., \& Schmitt, M. (2005). A metaanalysis on the correlation between the Implicit Association Test and explicit self-report measures. Personality and Social Psychology Bulletin, 31, 1369-1385. https://doi.org/10.1177/0146167205275613

Hu, J., Wang, Z., Liden, R. C. \& Sun, J. (2012). The influence of leader core self-evaluation on follower reports of transformational leadership. The Leadership Quarterly, 23, 860-868. http://dx.doi.org/10.1016/j.leaqua.2012.05.004

Inquisit 4.0.2.0 [Computer software]. (2011). Seattle, WA: Millisecond Software.

James, L. R., McIntyre, M. D., Glisson, C. A., Green, P. D., Patton, T. W., LeBreton, J. M., \& Williams, L. J. (2005). A conditional reasoning measure for aggression. Organizational Research Methods, 8, 69-99. https://doi.org/10.1177/1094428104272182

Johnson, R. E., Tolentino, A. L., Rodopman, O. B., \& Cho, E. (2010). We (sometimes) know not how we feel: Predicting job performance with an implicit measure of trait affectivity. Personnel Psychology, 63, 197-219. https://doi.org/10.1111/j.1744$\underline{6570.2009 .01166 . x}$ 
Judge, T. A. (2009). Core self-evaluations and work success. Current Directions in Psychological Science, 18, 58-62. https://doi.org/10.1111/j.1467-8721.2009.01606.x

Judge, T. A., Erez, A., \& Bono, J. E. (1998). The power of being positive: The relationship between positive self-concept and job performance. Human Performance, 11, 167187. https://doi.org/10.1080/08959285.1998.9668030

Judge, T. A., Erez, A., Bono, J. E., \& Thoresen, C. J. (2003). The Core Self-Evaluations Scale (CSES): Development of a measure. Personnel Psychology, 56, 303-331. https://doi.org/10.1111/j.1744-6570.2003.tb00152.x

Judge, T. A., \& Hurst, C. (2007). Capitalizing on one's advantages: Role of core selfevaluations. Journal of Applied Psychology, 92, 1212-1227. https://doi.org/10.1037/0021-9010.92.5.1212

Judge, T. A., Locke, E. A., \& Durham, C. C. (1997). The dispositional causes of job satisfaction: A core evaluations approach. Research in Organizational Behavior, 19, $151-188$.

Judge, T. A., Locke, E. A., Durham, C. C., \& Kluger, A. N. (1998). Dispositional effects on job and life satisfaction: The role of core evaluations. Journal of Applied Psychology, 83, 17-34. https://doi.org/10.1037/0021-9010.83.1.17

Judge, T. A., Piccolo, R. F., \& Kosalka, T. (2009). The bright and dark sides of leader traits: A review and theoretical extension of the leader trait paradigm. The Leadership Quarterly, 20, 855-875. https://doi.org/10.1016/j.leaqua.2009.09.004

Klavina, E., Schröder-Abé, M., \& Schütz, A. (2012). Facets of self-esteem at an implicit level? Investigation of implicit-explicit correlations and development of four IATs. Personality and Individual Differences, 53, 693-698. https://doi.org/10.1016/j.paid.2012.05.028 
Krause, S., Back, M. D., Egloff, B. \& Schmukle, S. C. (2016). Predicting self-confident behavior with implicit and explicit self-esteem measures. European Journal of Personality, 30, 648-662. https://doi.org/10.1002/per.2076

Leavitt, K., Fong, C. T., \& Greenwald, A. G. (2011). Asking about well-being gets you half an answer: Intra-individual processes of implicit and explicit job attitudes. Journal of Organizational Behavior, 32, 672-687. https://doi.org/10.1002/job.746

Luft, J., \& Ingham, H. (1955). The Johari window: A graphic model of interpersonal awareness. Paper presented at the Proceedings of the Western Training Laboratory in Group Development, Los Angeles, CA: UCLA Extension Office.

Lieberman, M. D. (2007). Social cognitive neuroscience: A review of core processes. Annual Review of Psychology, 58, 259-289. http://dx.doi.org/annurev.psych.58.110405.085654

Little, T. D., Cunningham, W. A., Shahar, G., \& Widaman, K. F. (2002). To parcel or not to parcel: Exploring the question, weighing the merits. Structural Equation Modeling, 9, 151-173. http://dx.doi.org/10.1207/S15328007SEM0902_ 1

Koole, S. L., Govorun, O., Cheng, C. M., \& Gallucci, M. (2009). Pulling yourself together: Meditation promotes congruence between implicit and explicit self-esteem. Journal of Experimental Social Psychology, 45, 1220-1226.

https://doi.org/10.1016/j.jesp.2009.05.018

Markus, H., \& Wurf, E. (1987). The dynamic self-concept: A social psychological perspective. Annual Review of Psychology, 38, 299-337. https://doi.org/10.1146/annurev.psych.38.1.299

McAbee, S. T., \& Connelly, B. S. (2016). A multi-rater framework for studying personality: The Trait-Reputation-Identity Model. Psychological Review, 123, 569-591. http://dx.doi.org/10.1037/rev0000035 
McClelland, D. C., Koestner, R., \& Weinberger, J. (1989). How do self-attributed and implicit motives differ? Psychological Review, 96, 690-702.

https://doi.org/10.1037/0033-295X.96.4.690

Morgeson, F. P., Campion, M. A., Dipboye, R. L., Hollenbeck, J. R., Murphy, K., \& Schmitt, N. (2007). Reconsidering the use of personality tests in personnel selection contexts. Personnel Psychology, 60, 683-729. https://doi.org/10.1111/j.1744$\underline{6570.2007 .00089 . x}$

Muthén, L. K., \& Muthén, B. O. (2012). Mplus User's Guide (7th ed.). Los Angeles, CA: Muthén \& Muthén.

Murphy, K.R. (2012). Individual Differences. In N. Schmitt (Eds.), The Oxford Handbook of Personnel Assessment and Selection (pp. 31-47). New York, NY: Oxford University Press. https://doi.org/10.1093/oxfordhb/9780199732579.013.0003

Nosek, B. (2005). Moderators of the relationship between implicit and explicit evaluation. Journal of Experimental Psychology: General, 134, 565-584. https://doi.org/10.1037/0096-3445.134.4.565

Nosek, B., Greenwald, A. G., \& Banaji, M. (2007). The Implicit Association Test at age 7: A methodological and conceptual review. In J. Bargh (Ed.), Automatic Processes in Social Thinking and Behavior (pp. 265-292). Philadelphia, PA: Psychology Press.

Nosek, B. A., \& Smyth, F. L. (2007). A multitrait-multimethod validation of the Implicit Association Test: Implicit and explicit attitudes are related but distinct constructs. Experimental Psychology, 54, 14-29. https://doi.org/10.1027/1618-3169.54.1.14

Nübold, A., \& Maier, G. (2012). The concept of state core self-evaluations - Presentation of a new measure and a leadership experiment. Paper presented at the Biennial Conference of the Institute of Work Psychology, Sheffield, UK. 
Oh, I., Wang, G., \& Mount, M. K. (2011). Validity of observer ratings of the Five-Factor Model of personality traits: A meta-analysis. Journal of Applied Psychology, 96, 762773. https://doi.org/10.1037/a0021832

O'Neill, T. A., McLarnon, M. J., Xiu, L., \& Law, S. J. (2016). Core self-evaluations, perceptions of group potency, and job performance: The moderating role of individualism and collectivism cultural profiles. Journal of Occupational and Organizational Psychology, 89, 447-473. https://doi.org/10.1111/joop.12135

Oswald, F. L., Mitchell, G., Blanton, H., Jaccard, J., \& Tetlock, P. E. (2013). Predicting ethnic and racial discrimination: A meta-analysis of IAT criterion studies. Journal of Personality and Social Psychology, 105, 171-192. https://doi.org/10.1037/a0032734

Oswald, F. L., Mitchell, G., Blanton, H., Jaccard, J., \& Tetlock, P. E. (2015). Using the IAT to predict ethnic and racial discrimination: Small effect sizes of unknown societal significance. Journal of Personality and Social Psychology, 108, 562-571. http://dx.doi.org/10.1037/pspa0000023

Paulhus, D. L., \& John, O. P. (1998). Egoistic and moralistic biases in self-perception: The interplay of self-deceptive styles with basic traits and motives. Journal of Personality, 66, 1025 - 1060. https://doi.org/10.1111/1467-6494.00041

Perugini, M., \& Banse, R. (2007). Personality, implicit self-concept and automaticity. European Journal of Personality, 21, 257-261. https://doi.org/10.1002/per.637

Rotundo, M., \& Sackett, P.R. (2002). The relative importance of task, citizenship, and counterproductive performance to global ratings of job performance: A policycapturing approach. Journal of Applied Psychology, 87, 66-80.

https://doi.org/10.1037/0021-9010.87.1.66 
Schnabel, K., \& Asendorpf, J. B. (2010). The self-concept: New insights from Implicit measurement procedures. In I. B. Gawronski, \& B. K. Payne (Eds.), Handbook of implicit social cognition (pp. 408-425). New York, NY: Guilford Press.

Schnabel, K., Asendorpf, J. B., \& Greenwald A. G. (2008). Using Implicit Association Tests for the assessment of implicit personality self-concept. In G.J. Boyle, Matthews, G., Saklofske, H. (Eds.), Handbook of personality theory and testing (pp. 508-528). London: Sage. https://doi.org/10.4135/9781849200479.n24

Schröder-Abé, M., Rudolph, A., \& Schütz, A. (2007). High implicit self-esteem is not necessarily advantageous: discrepancies between explicit and implicit self-esteem and their relationship with anger expression and psychological health. European Journal of Personality, 21, 319-339. https://doi.org/10.1002/per.626

Staufenbiel, T., \& Hartz, C. (2000). Organizational Citizenship Behavior: Entwicklung und Validierung eines ersten Messinstruments [Organizational citizenship behavior: Development and validation of a measurement instrument]. Diagnostica, 46, 73-83. https://doi.org/10.1026//0012-1924.46.2.73

Strack, F., \& Deutsch, R. (2004). Reflective and impulsive determinants of social behavior. Personality and Social Psychology Review, 8, 220-247. https://doi.org/10.1207/s15327957pspr0803_1

Stumpp, T., Muck, P., Hülsheger, U., Judge, T. A. \& Maier, G. (2010). Core self-evaluations in Germany: Validation of a German measure and its relationships with career success. Applied Psychology: An International Review, 59, 674-700. https://doi.org/10.1111/j.1464-0597.2010.00422.x

Sun, S. \& van Emmerik, H. (2015). Are proactive personalities always beneficial? Political skill as a moderator. Journal of Applied Psychology, 100, 966-975. https://doi.org/10.1037/a0037833 
Uhlmann, E. L., Leavitt, K., Menges, J. I., Koopman, J., Howe, M., \& Johnson, R. E. (2012). Getting explicit about the implicit: A taxonomy of implicit measures and guide for their use in organizational research. Organizational Research Methods, 15, 533-601. https://doi.org/10.1177/1094428112442750

Vecchione, M., Dentale, F., Alessandri, G., \& Barbaranelli, C. (2014). Fakability of implicit and explicit measures of the Big Five: Research findings from organizational settings. International Journal of Selection and Assessment, 22, 211-218. https://doi.org/10.1111/ijsa.12070

Vecchione, M., Dentale, F., Alessandri, G., Imbesi, M.T., Barbaranelli, C., \& Schnabel, K. (2016). On the applicability of the big five implicit association test in organizational settings. Current Psychology, 1-10. https://doi.org/10.1007/s12144-016-9455-x

Williams, L. J., \& Anderson, S. E. (1991). Job satisfaction and organizational commitment as predictors of organizational citizenship and in-role behavior. Journal of Management, 17, 601-617. https://doi.org/10.1177/014920639101700305

Wilson, T. D., \& Dunn, E. W. (2004). Self-knowledge: Its limits, value, and potential for improvement. Annual Review of Psychology, 55, 493-518. https://doi.org/10.1146/annurev.psych.55.090902.141954

Williams, M., \& Gardiner, E. (2018). The power of personality at work: Core self-evaluations and earnings in the United Kingdom. Human Resource Management Journal, 28, 4560. https://doi.org/10.1146/10.1111/1748-8583.12162

Williams, L. J., \& O'Boyle, E. H. (2008). Measurement models for linking latent variables and indicators: A review of human resource management research using parcels. Human Resource Management Review, 18, 233-242. https://doi.org/10.1016/j.hrmr.2008.07.002 
Table 1

Implicit Association Test of core self-evaluations: Task sequence and categories.

\begin{tabular}{cclll}
\hline & & & \multicolumn{2}{c}{ Response key assignment } \\
\cline { 4 - 5 } Block & \multirow{2}{*}{ No. of trials } & \multicolumn{1}{c}{ Task } & \multicolumn{1}{c}{ Left key } & \multicolumn{1}{c}{ Right key } \\
\hline 1 & 20 & Attribute discrimination & Me & Other \\
2 & 20 & Target discrimination & Positive & Negative \\
3 & 80 & Initial combined task & Positive or Me & Negative or Other \\
4 & 20 & Reversed target discrimination & Negative & Positive \\
5 & 80 & Reversed combined task & Negative or Me & Positive or Other \\
\hline
\end{tabular}

Note. Items used for categories: "Me": I, me, my, self; "Other": other, they, them, their;

"Positive": competent, stable, satisfied, certain, independent, optimistic, confident, valuable;

"Negative": incompetent, unstable, dissatisfied, uncertain, dependent, pessimistic, shy, valueless. The original German stimuli can be obtained from the first author. 
Table 2

Descriptive Statistics, Correlations, and Reliabilities

\begin{tabular}{llcccccccc}
\hline \multicolumn{1}{c}{ Variable } & $M$ & $S D$ & 1 & 2 & 3 & 4 & 5 & 6 \\
\hline 1. & CSE self & 4.88 & 0.57 & .83 & & & & & \\
2. & CSE implicit & 0.58 & 0.32 & .13 & .73 & & & & \\
3. & CSE pacq & 5.05 & 0.57 & $.30 * *$ & .10 & .80 & & & \\
4. & Task Perf. col & 6.21 & 0.59 & .11 & $.15^{\dagger}$ & .10 & .86 & & \\
5. & OCB col & 5.49 & 0.64 & $.20^{*}$ & $.23^{* *}$ & $.22^{* *}$ & $.68^{* *}$ & $\mathbf{. 8 5}$ & \\
6. & Income & 40744.46 & 26233.20 & .06 & $.18^{*}$ & $.21 * *$ & .13 & $.21 *$ & - \\
\hline
\end{tabular}

Note. $N=153$ employees (rated by 153 colleagues and 153 personal acquaintances). $\mathrm{CSE}=$ Core Self-Evaluations; OCB $=$ organizational citizenship behaviour; Perf. = performance; self = self-ratings; pacq = personal acquaintance ratings; col = colleague ratings. The numbers in bold on the diagonal are reliability coefficients.

$* * p<.01,{ }^{*} p<.05,{ }^{\dagger} \mathrm{p}<.10$ 
Table 3

Hierarchical Regressions on Task Performance, OCB, and Income

\begin{tabular}{|c|c|c|c|c|c|c|}
\hline \multirow[t]{2}{*}{ Variable } & \multicolumn{2}{|c|}{$\begin{array}{c}\text { Task } \\
\text { Performance }\end{array}$} & \multicolumn{2}{|c|}{ OCB } & \multicolumn{2}{|c|}{ Income } \\
\hline & & & & & & \\
\hline CSE self & .11 & $(.08)$ & $.22 *$ & $(.09)$ & 2839.08 & (3715.27) \\
\hline $\mathrm{R}^{2}$ & .01 & & $.04 *$ & & .00 & \\
\hline \multicolumn{7}{|l|}{ Step $1 b$} \\
\hline CSE pacq & .10 & (.09) & $.24 * *$ & $(.09)$ & $9787.97 * *$ & $(3682.85)$ \\
\hline $\mathrm{R}^{2}$ & .01 & & $.05^{* *}$ & & $.04 * *$ & \\
\hline \multicolumn{7}{|l|}{ Step $2 a$} \\
\hline CSE self & .09 & $(.08)$ & $.19 *$ & $(.09)$ & 1754.84 & $(3700.41)$ \\
\hline CSE implicit & .25 & $(.15)$ & $.40^{*}$ & $(.16)$ & $14735.45^{*}$ & $(6644.01)$ \\
\hline$\Delta R^{2}$ & .02 & & $.04 *$ & & $.03 *$ & \\
\hline Overall $\mathrm{R}^{2}$ & .03 & & $.08^{* *}$ & & $.04^{\dagger}$ & \\
\hline \multicolumn{7}{|l|}{ Step $2 b$} \\
\hline CSE pacq & .09 & (.09) & $.22 *$ & $(.09)$ & $9002.17 *$ & $(3662.57)$ \\
\hline CSE implicit & $.25^{\dagger}$ & $(.15)$ & $.41^{* *}$ & $(.16)$ & $13503.50 *$ & $(6496.57)$ \\
\hline$\Delta R^{2}$ & $.02^{\dagger}$ & & $.04 * *$ & & $.03 *$ & \\
\hline Overall $\mathrm{R}^{2}$ & .03 & & $.09 * *$ & & $.07 * *$ & \\
\hline \multicolumn{7}{|l|}{ Step $2 c$} \\
\hline CSE self & .09 & $(.09)$ & $.17^{\dagger}$ & $(.09)$ & -110.37 & (3831.72) \\
\hline CSE pacq & .08 & $(.09)$ & $.19^{*}$ & $(.09)$ & $9821.93 *$ & (3878.62) \\
\hline$\Delta R^{2}$ & .01 & & $.03 *$ & & $.04 *$ & \\
\hline Overall $\mathrm{R}^{2}$ & .02 & & $.07 * *$ & & $.05^{*}$ & \\
\hline \multicolumn{7}{|l|}{ Step 3} \\
\hline CSE self & .07 & (.09) & .14 & $(.09)$ & -955.92 & (3811.17) \\
\hline CSE pacq & .07 & $(.09)$ & $.18^{\dagger}$ & $(.09)$ & $9286.12 *$ & $(3844.53)$ \\
\hline CSE implicit & .24 & $(.15)$ & $.38 *$ & $(.16)$ & $13678.26^{*}$ & $(6554.10)$ \\
\hline$\Delta R^{2}$ & .02 & & $.04 *$ & & $.03^{*}$ & \\
\hline Overall $\mathrm{R}^{2}$ & .03 & & $.10^{* *}$ & & $.07 *$ & \\
\hline
\end{tabular}

Note. $N=153$ employees (rated by 153 colleagues and 153 personal acquaintances). CSE $=$ Core Self-Evaluations; OCB = organizational citizenship behaviour; self = self-ratings; pacq $=$ personal acquaintance ratings. Values are unstandardized regression coefficients (standard error estimates are listed in parentheses). ${ }^{* *} p<.01,{ }^{*} p<.05,{ }^{\dagger} \mathrm{p}<.10$ 